\title{
Femtosecond Laser-assisted Intrastromal MyoRing Implantation in Eyes with Keratoconus and High Myopia
}

\author{
${ }^{1}$ Maksim V Sinitsyn, ${ }^{2}$ Nikolay P Pashtayev, ${ }^{3}$ Nadezhda A Pozdeyeva
}

\begin{abstract}
Aim: To analyze the clinical and functional outcomes of correction of high myopia in eyes with the first stage of keratoconus using femtosecond laser-assisted intrastromal MyoRing implantation.
\end{abstract}

Materials and methods: Thirty eyes (15 patients) with the first stage of keratoconus and high myopia underwent femtosecond laser-assisted intrastromal MyoRing implantation. Mean corneal thickness was $468 \pm 12.4 \mu \mathrm{m}$. MyoRings were inserted in the intrastromal pockets with diameter $9.0 \mathrm{~mm}$ at the depth of $300 \mu \mathrm{m}$ using femtosecond laser IntraLase FS $60 \mathrm{kHz}$.

Results: Mean uncorrected visual acuity (UCVA) value increased from $1.2 \pm 0.03$ to $0.3 \pm 0.1 \log$ MAR 6 months after operation, mean best corrected visual acuity (BCVA) value increased from $0.24 \pm 0.09$ to $0.18 \pm 0.03 \log M A R$. Then UCVA and BCVA values remained practically unaltered during the whole follow-up period.

Conclusion: The MyoRing implantation stabilizes the keratoconus by enhancing the biomechanical properties of the cornea and simultaneously improves visual acuity due to correction of high myopia.

Keywords: Femtosecond laser, High myopia, MyoRing.

How to cite this article: Sinitsyn MV, Pashtayev NP, Pozdeyeva NA. Femtosecond Laser-assisted Intrastromal MyoRing Implantation in Eyes with Keratoconus and High Myopia. Int J Kerat Ect Cor Dis 2018;7(1):6-11.

Source of support: Nil

Conflict of interest: None

\section{INTRODUCTION}

Recently, a new method of intrastromal MyoRing implantation for stabilizing keratoconus and correction

\footnotetext{
${ }^{1}$ Ophthalmologist, ${ }^{2}$ Professor and Clinic Director, ${ }^{3}$ Professor and Deputy Director

${ }^{1}$ Department of Ambulatory Surgery, The S. Fyodorov Eye Microsurgery Federal State Institution, Cheboksary, Chuvashia Russian Federation

${ }^{2,3}$ The Cheboksary Branch of the S. Fyodorov Eye Microsurgery Federal State Institution, Cheboksary, Chuvashia, Russian Federation

Corresponding Author: Maksim V Sinitsyn, Ophthalmologist Department of Ambulatory Surgery, The S. Fyodorov Eye Microsurgery Federal State Institution, Cheboksary, Chuvashia Russian Federation, e-mail: mntksinicin@mail.ru
}

of concomitant high myopia was proposed. ${ }^{1,2}$ Due to applanation of corneal surface, it allows correction of high myopia with spherical component up to $20 \mathrm{D}$ and cylindrical component up to $-4.5 \mathrm{D}$ in eyes with keratoconus. ${ }^{3,4}$ The MyoRing is inserted into the corneal pocket formed with the specialized mechanical microkeratome or femtosecond laser. ${ }^{5}$ The diameter of the pocket is $9.0 \mathrm{~mm}$ and its depth is $300 \mu \mathrm{m}$. MyoRing is made of polymeric material based on polymethylmethacrylate. The MyoRing diameter ranges from 5.0 to $8.0 \mathrm{~mm}$ with a step of $1 \mathrm{~mm}$, and its height ranges from 200 to $400 \mu \mathrm{m}$ with a step of $20 \mu \mathrm{m} .{ }^{6,7}$

\section{AIM}

The purpose of the present study is to make an analysis of clinical and functional outcomes of correction of high myopia using femtosecond laser-assisted intrastromal MyoRing implantation in eyes with the first stage of keratoconus.

\section{MATERIALS AND METHODS}

We have operated on 30 eyes of 15 patients with the first stage of keratoconus (according to the Amsler-Krumeich classification $)^{4}$ and high myopia. All patients underwent femtosecond laser-assisted intrastromal MyoRing (Dioptex, Austria) implantation. The mean corneal thickness was $468 \pm 12.4 \mu \mathrm{m}$. The mean age of patients was $28 \pm 4$ years. Ocular media of all eyes were clear. Femtosecond laser-assisted intrastromal MyoRing implantation was performed in two stages. Stage I represented creation of an intrastromal pocket with diameter $9.0 \mathrm{~mm}$ at the depth of $300 \mu \mathrm{m}$ and an incision tunnel $1.0 \mathrm{~mm}$ long and $4.0 \mathrm{~mm}$ wide using femtosecond laser IntraLase FS 60 $\mathrm{kHz}$ (AMO, USA). At stage II, the MyoRing was inserted in the corneal pocket. The MyoRing's diameter was 5.0 $\mathrm{mm}$, its height ranged from 280 to $320 \mu \mathrm{m}$, and the width was $0.5 \mathrm{~mm}$. The MyoRing's parameters were calculated using nomogram (Daxer 2010) ${ }^{2}$ taking into account the minimum corneal thickness and spherical equivalent (SE) value.

Before and after operation, we examined the anterior eye segment with Pentacam HR (Oculus, Germany), optical coherence tomograph RTVue 100 CAM (Optovue, Inc., USA), corneal topographer (Tomey 4, Japan), ocular 
response analyzer (Reichert, USA), and confocal microscope Confoscan 4 (Nidek, Japan). The mean postoperative follow-up period was 12 months (6-14 months).

Data were analyzed on a personal computer with statistical software Statistica 6.1 ("StatSoft", USA). Accuracy of variations was estimated with parametric criterion for dependent variables (Student's t-test, p) due to the symmetrical distribution of the aggregate value of the parameters. Variations between the samples were considered significant at $\mathrm{p}<0.05$.

\section{RESULTS}

There were no preoperative and postoperative complications in all patients. Early postoperative period was uneventful. All eyes were quiet during the first few days after surgery. The ocular media were clear. Some patients had local subconjunctival hemorrhage due to vacuum ring application. MyoRings were implanted into intrastromal pockets at the estimated depth (Fig. 1).

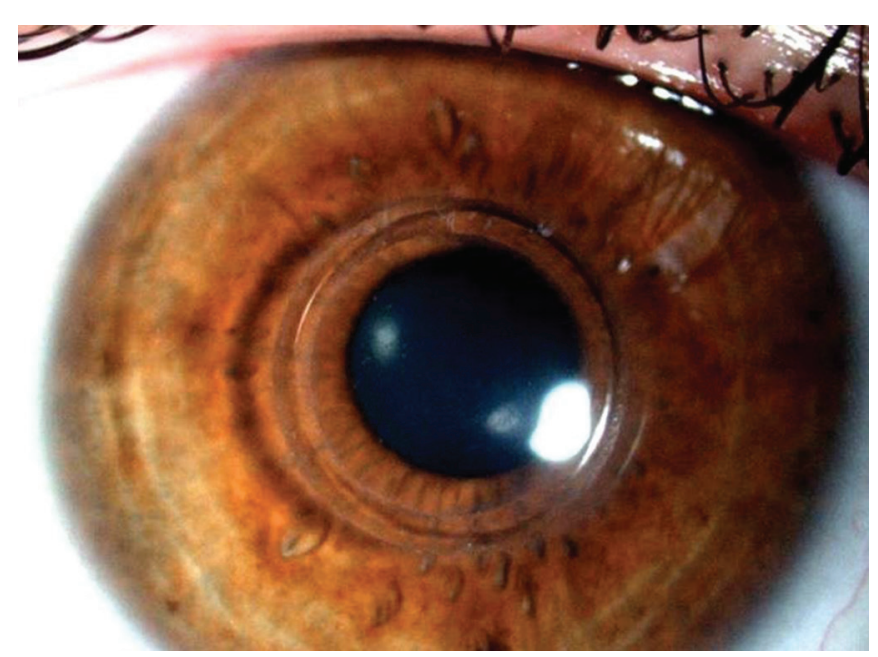

Fig. 1: Slitlamp photograph of the operated eye on the first postoperative day after femtolaser-assisted intrastromal implantation of MyoRing
To evaluate the results of the study for their efficiency, safety, predictability, and stability were defined.

\section{Efficiency}

To evaluate the operation efficiency, we analyzed the ratio of postoperative UCVA (UCVA postoperative) to preoperative BCVA (BCVA preoperative). The efficiency coefficient was $1.1 \pm 0.39($ Graph 1$)$.

\section{Safety}

None of the patients lost a single BCVA line postoperatively. BCVA did not change in $67 \%$ (20 eyes), the acquisition of 1 BCVA line in Golovin-Sivtsev table was observed in $17 \%$ (5 eyes), the acquisition of two lines was observed in $7 \%$ (2 eyes), and the acquisition of three lines was observed in 10\% (3 eyes) (Graph 2 ). The safety coefficient was $1.3 \pm 0.42(\mathrm{p}=0.05)$.

\section{Predictability}

The predictability of the result (correction accuracy) was calculated by the percent of eyes with deviation within the ranges of $\pm 0.5, \pm 1.0$, and \pm 2.0 D of the planned refraction 1 year after operation. The SE predictability within the range of $\pm 0.5 \mathrm{D}$ was in $47 \%$ (14 eyes), within the range of $\pm 1.0 \mathrm{D}$, it was in $60 \%$ (18 eyes), and within the range of $\pm 2.0 \mathrm{D}$, it was in $100 \%$ (30 eyes) ( $\mathrm{p}=0.045$ ) (Graphs 3 and 4). The predictability of the cylindrical component within the range of $\pm 0.5 \mathrm{D}$ was $47 \%$ (14 eyes) and within the range of $\pm 1.0 \mathrm{D}$, it was $87 \%$ (26 eyes) $(\mathrm{p}=0.002)($ Graph 5).

\section{Stability}

Using refractometry and corneal topographer, the stability of parameters was observed 10 to 12 months after operation. The mean SE refractive regress during

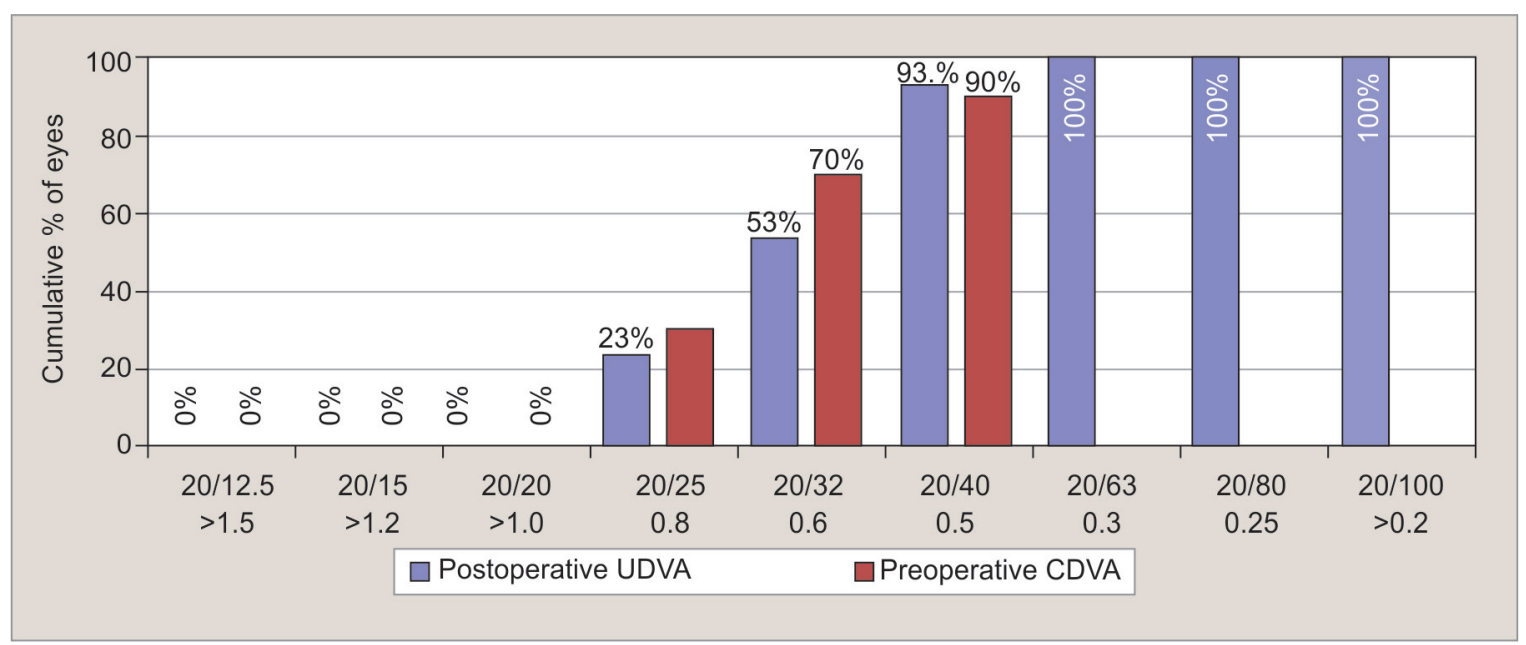

Graph 1: Uncorrected distance visual acuity after femtolaser-assisted intrastromal implantation of MyoRing 


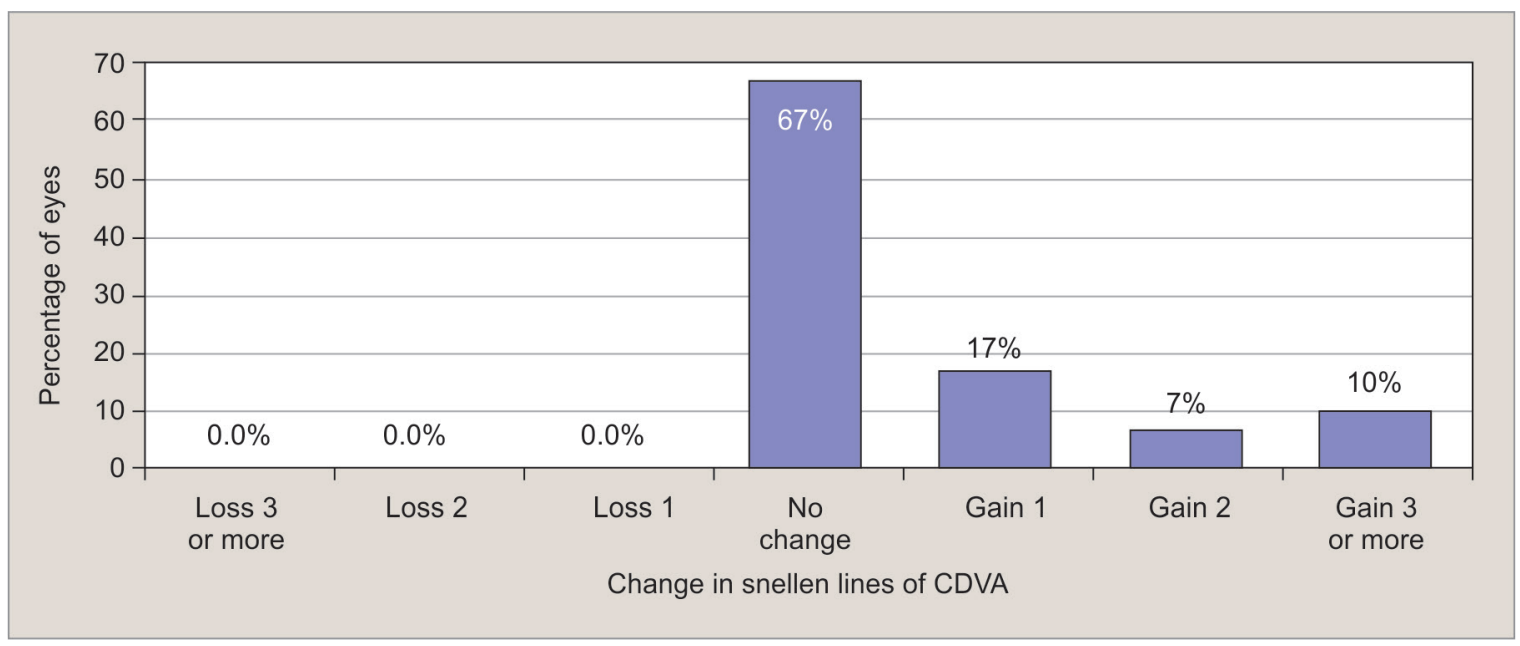

Graph 2: Change in corrected distance visual acuity after femtolaser-assisted intrastromal implantation of MyoRing

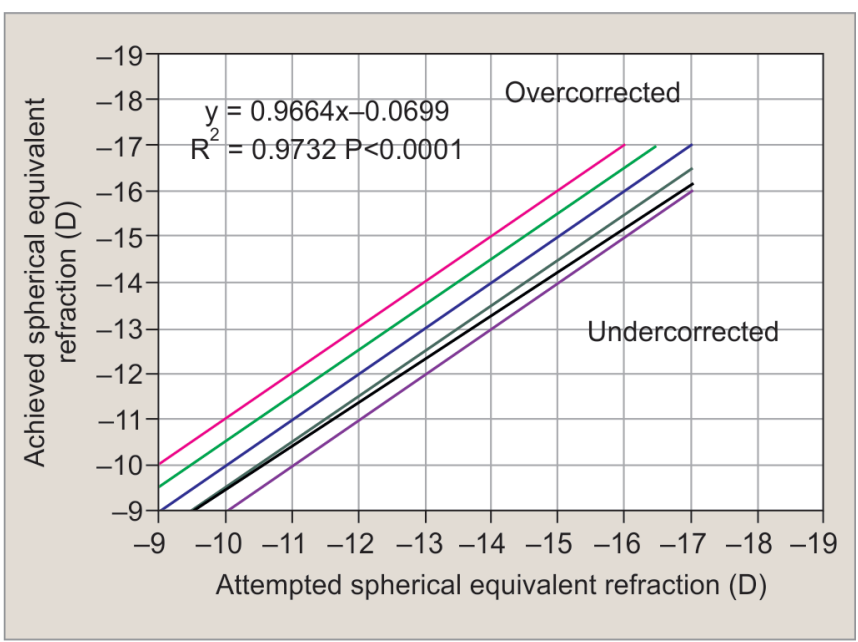

Graph 3: Attempted vs achieved SE after femtolaser-assisted intrastromal implantation of MyoRing

the last 6 months of follow-up period was $-0.1 \pm 0.06 \mathrm{D}$ (Graph 6).

The mean UCVA value increased from $1.2 \pm 0.03$ $\log$ MAR to $0.3 \pm 0.1 \log$ MAR 6 months after operation, and the mean BCVA value increased from $0.24 \pm 0.09$ $\log$ MAR $0.18 \pm 0.03 \log$ MAR (Table 1). After that, UCVA and BCVA values remained unchanged throughout the follow-up period. Six months after operation, the spherical refraction component decreased from $-12.85 \pm 2.72$ to $-0.75 \pm 0.35 \mathrm{D}$. The cylindrical component decreased from $-2.28 \pm 1.53$ to $-1.49 \pm 1.0 \mathrm{D}$. By the $12^{\text {th }}$ month of follow-up, the spherical component had slightly increased up to $-1.1 \pm 0.25 \mathrm{D}$ and the cylindrical component had decreased to $-0.99 \pm 0.45 \mathrm{D}$.

According to pachymetry results, the minimum corneal thickness remained practically unaltered at the level of $470 \pm 10 \mu \mathrm{m}(\mathrm{p}=0.0322)$.

\section{Analysis of Corneal Biomechanics Alteration}

In 6 months after operation, the corneal resistance factor (CRF) increased from $8.43 \pm 1.49$ to $8.6 \pm 0.98 \mathrm{~mm} \mathrm{Hg}$. The corneal hysteresis $(\mathrm{CH})$ increased from $8.72 \pm 1.31$ to $8.9 \pm$ $1.40 \mathrm{~mm} \mathrm{Hg}$. Then, by the 12th month of follow-up, CRF increased up to $8.8 \pm 1.21 \mathrm{~mm} \mathrm{Hg}$ and $\mathrm{CH}$ increased up to $9.1 \pm 1.23 \mathrm{~mm} \mathrm{Hg}$.

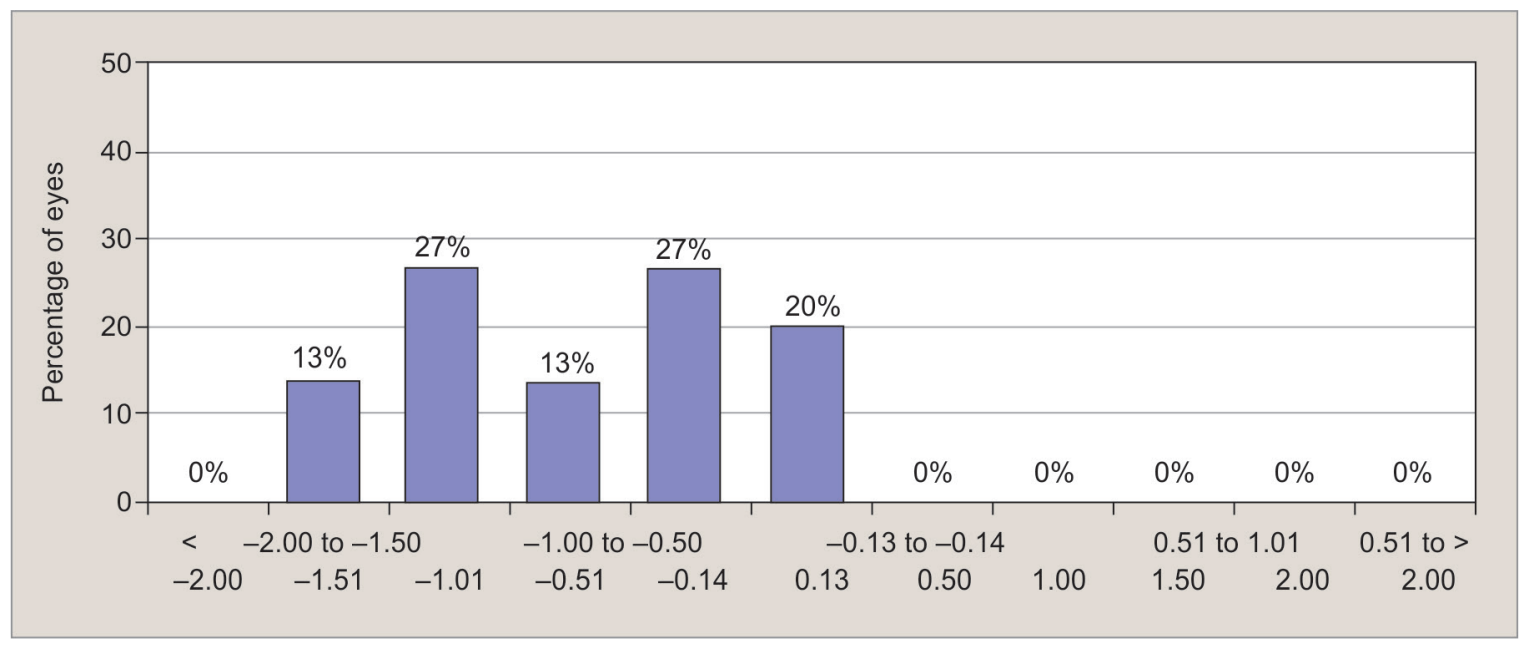

Graph 4: The SE refractive accuracy after femtolaser-assisted intrastromal implantation of MyoRing 


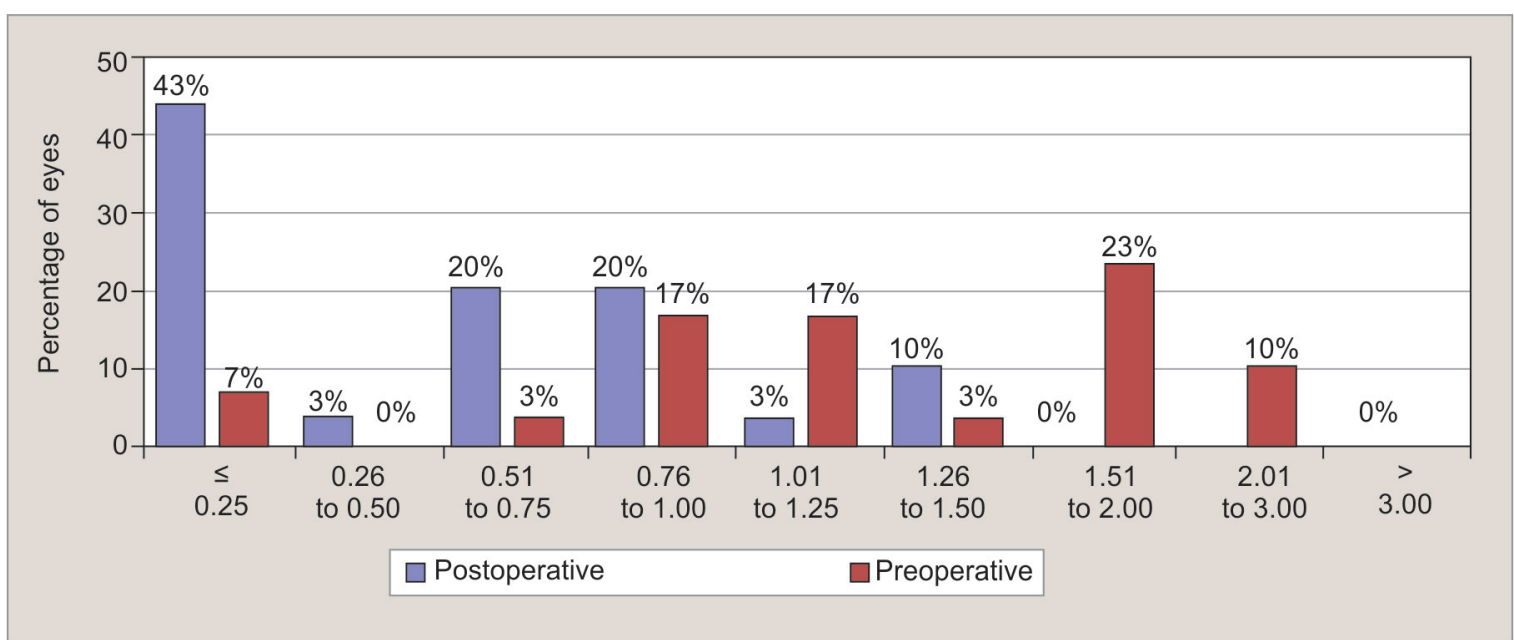

Graph 5: Refractive astigmatism after femtolaser-assisted intrastromal implantation of MyoRing

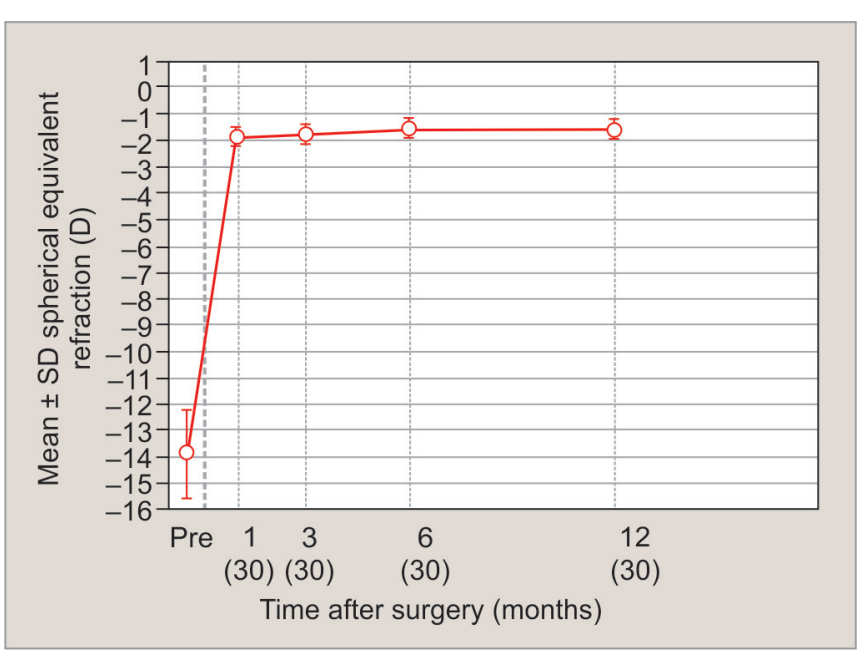

Graph 6: Stability of SE refraction after femtolaser-assisted intrastromal implantation of MyoRing

\section{Confocal Biomicroscopy}

The preoperative confocal microscopy showed that the corneal stroma was clear without any morphological peculiarities. One month after operation in the central optic zone, some active keratocytes were visible in the posterior stroma (Fig. 2). At the corneal pocket edge, we visualized moderate stromal clarity disturbance and a few hyperreflective spots (Fig. 3) of different form and size, accumulation of hyperreflective keratocytes, and stromal nerve thickening (Fig. 4), indicating the activation of metabolic processes in the cornea. Structural and morphological stromal changes were visualized only in the pocket area with moderate folding (Fig. 5) and hypocellularity. The MyoRing was hyperreflective and it made it difficult to visualize the posterior stroma and endothelium. Above the MyoRing a moderate clarity disturbance was visualized in the anterior stroma due to the shadow cast by the hyperreflective ring. In the corneal tunnel area, the stroma was healing with an epithelial plug in five eyes $(17 \%)$, neither epithelial cell invasion into intrastromal pocket nor corneal tunnel was observed (Fig. 6). The intact adjacent stroma was unaltered. Six months after operation, we visualized the decrease of active keratocytes (Fig. 7), reduction of stromal nerve thickness (Fig. 8), stromal folds (Fig. 9), and solitary hyperreflective spots (Fig. 10). Twelve months after operation, the keratocytes morphology and stromal nerve thickness were comparable to the preoperative. Solitary hyperreflective spots (Fig. 11) and mild stromal folds (Fig. 12) were visualized in some cases.

\section{CONCLUSION}

Clinical and functional analysis of the correction of high myopia in eyes with the first stage of keratoconus using femtosecond laser-assisted intrastromal MyoRing implantation

Table 1: Preoperative and postoperative clinical findings $(n=30)$

\begin{tabular}{|c|c|c|c|c|c|}
\hline \multirow[b]{2}{*}{ Parameter } & \multirow{2}{*}{$\begin{array}{c}\text { Baseline } \\
\text { Mean } \pm S D\end{array}$} & \multicolumn{2}{|c|}{6 months postoperative } & \multicolumn{2}{|c|}{12 months postoperative } \\
\hline & & Mean $\pm S D$ & $p$-value & Mean $\pm S D$ & $p$-value \\
\hline UCVA (logMAR) & $1.2 \pm 0.03$ & $0.3 \pm 0.1$ & 0.0001 & $0.3 \pm 0.11$ & 0.00001 \\
\hline BCVA (logMAR) & $0.24 \pm 0.09$ & $0.18 \pm 0.03$ & 0.0088 & $0.17 \pm 0.02$ & 0.00832 \\
\hline Sphere, D & $-12.85 \pm 2.72$ & $-0.75 \pm 035$ & 0.000 & $-1.1 \pm 0.25$ & 0.00012 \\
\hline Cylinder, D & $-2.28 \pm 1.53$ & $-1.49 \pm 1.0$ & 0.0168 & $-0.99 \pm 0.45$ & 0.03221 \\
\hline CRF, mm Hg & $8.43 \pm 1.49$ & $8.6 \pm 0.98$ & 0.0183 & $8.8 \pm 1.21$ & 0.01621 \\
\hline $\mathrm{CH}, \mathrm{mm} \mathrm{Hg}$ & $8.72 \pm 1.31$ & $8.9 \pm 1.40$ & 0.05752 & $9.1 \pm 1.23$ & 0.01258 \\
\hline
\end{tabular}

SD: Standard deviation 


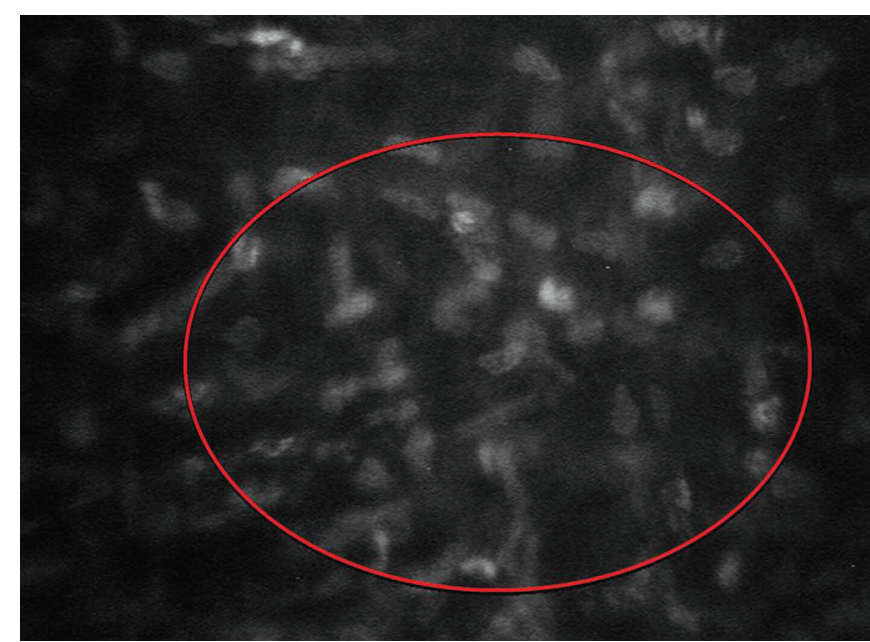

Fig. 2: Confocal microscopy active keratocytes in the posterior stroma 1 month after femtolaser-assisted intrastromal implantation of MyoRing

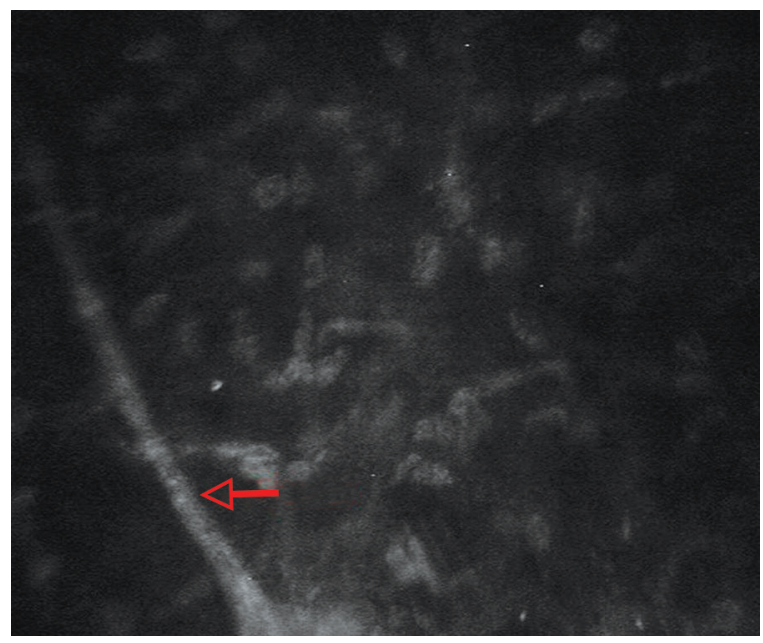

Fig. 4: Confocal microscopy thickened stromal nerve 1 month after femtolaser-assisted intrastromal implantation of MyoRing

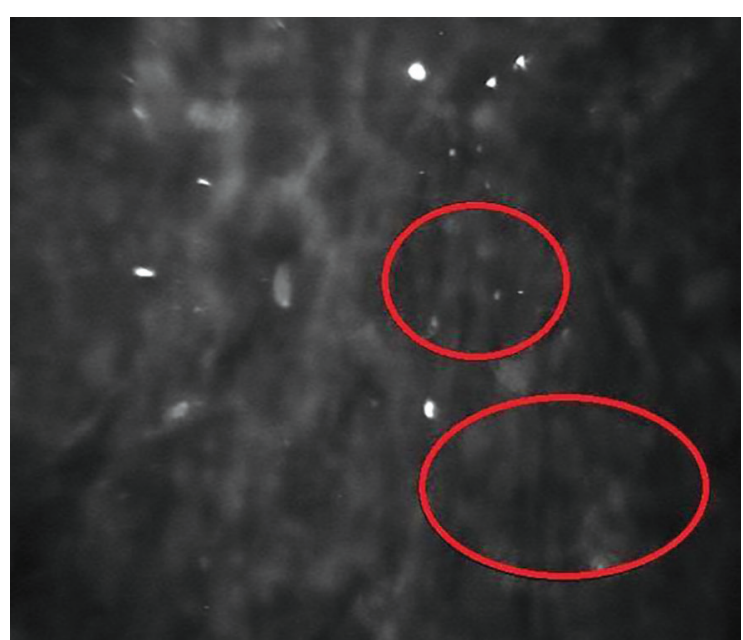

Fig. 6: Confocal microscopy epithelial plug in the corneal tunnel 1 month after femtolaser-assisted intrastromal implantation of MyoRing

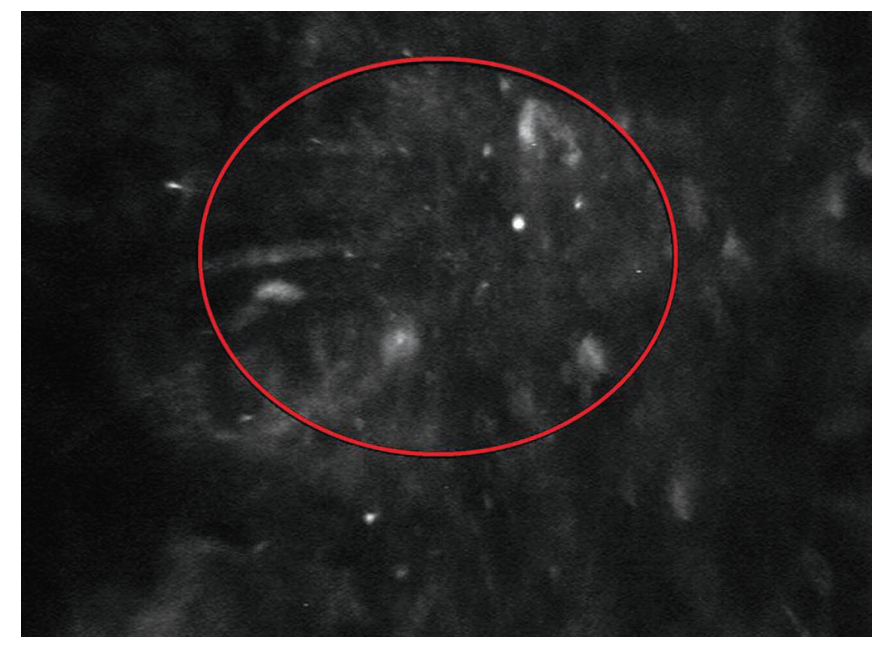

Fig. 3: Confocal microscopy hyperreflective spots in the corneal pocket 1 month after femtolaser-assisted intrastromal implantation of MyoRing

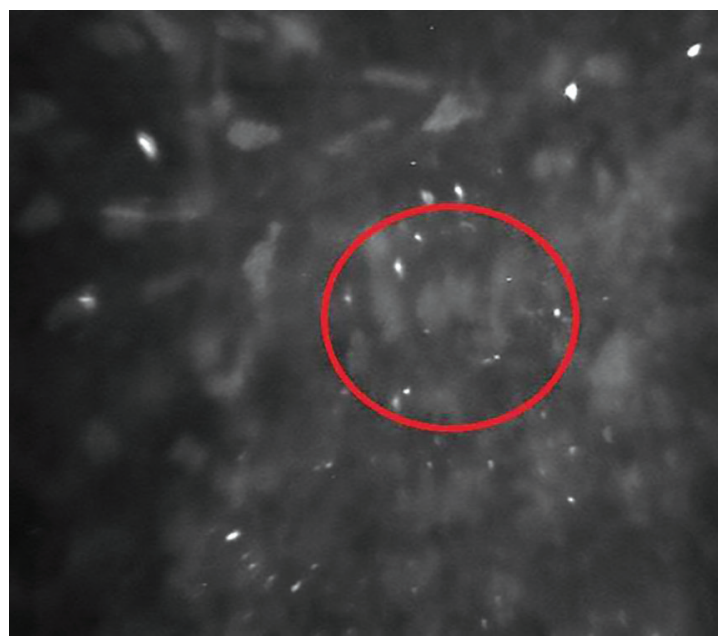

Fig. 5: Confocal microscopy moderate folding of stroma 1 month after femtolaser-assisted intrastromal implantation of MyoRing

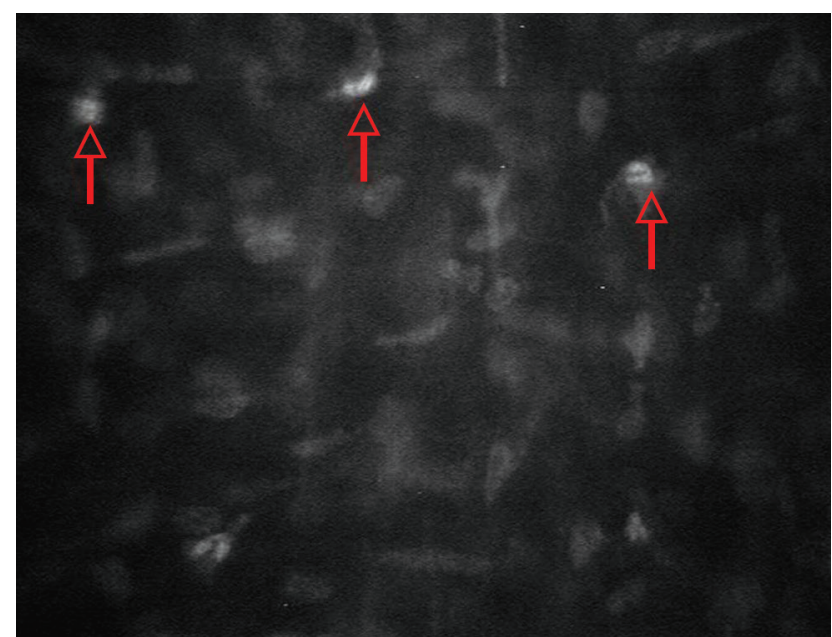

Fig. 7: Confocal microscopy reduction in the number of active keratocytes 6 months after femtolaser-assisted intrastromal implantation of MyoRing 


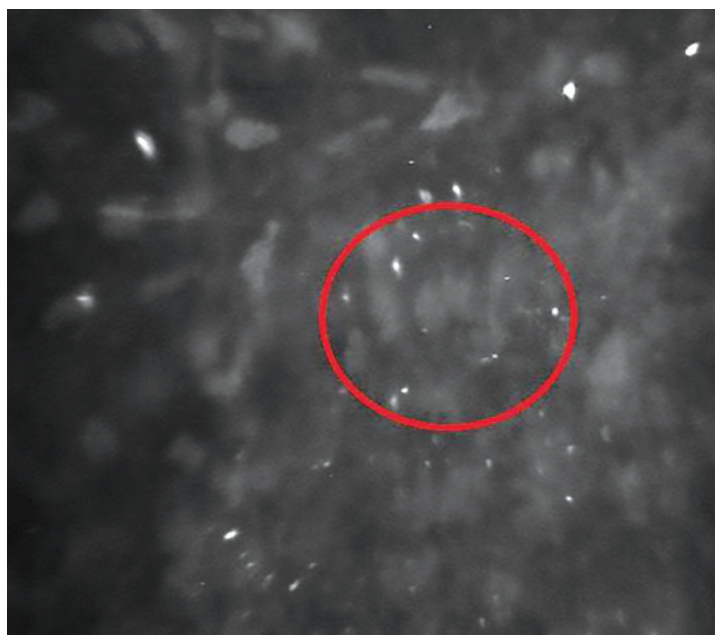

Fig. 8: Confocal microscopy reduction of stromal nerve thickness 6 months after femtolaser-assisted intrastromal implantation of MyoRing

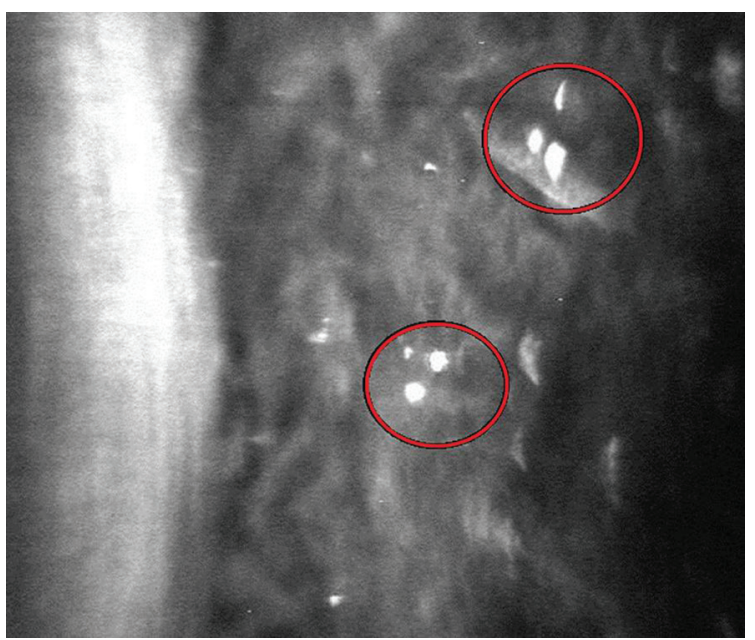

Fig. 10: Confocal microscopy solitary hyperreflective spots 6 months after femtolaser-assisted intrastromal implantation of MyoRing

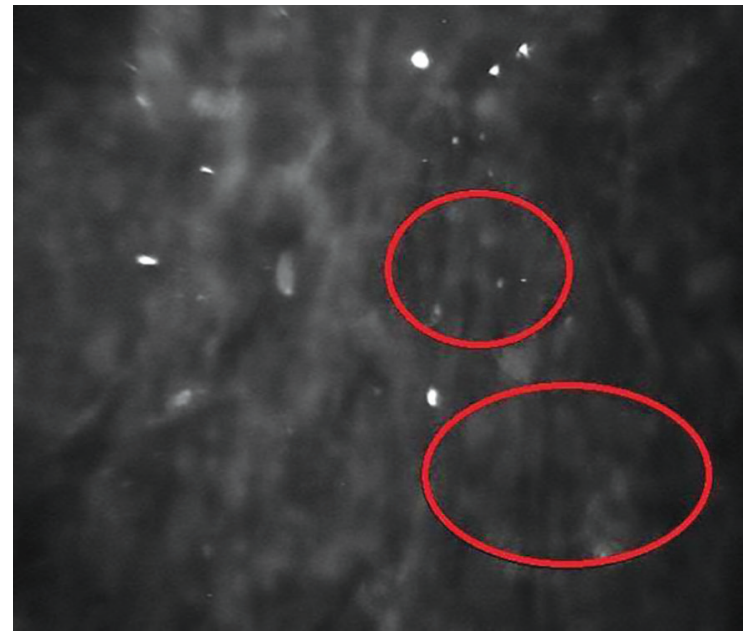

Fig. 12: Confocal microscopy mild stromal folds 12 months after femtolaser-assisted intrastromal implantation of MyoRing

within a 12-month follow-up period showed stabilization of the keratoconus by enhancing the biomechanical properties of the cornea and simultaneously correcting high myopia.

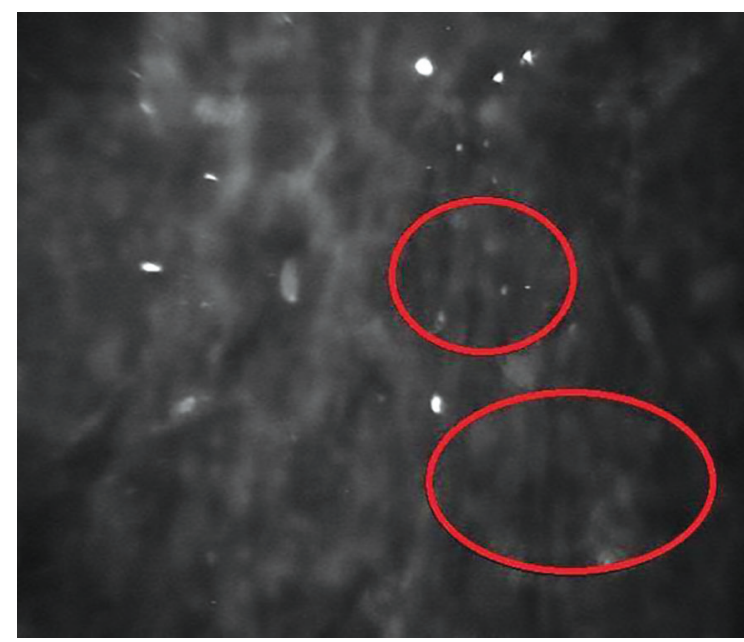

Fig. 9: Confocal microscopy reduction in the severity of stromal folds 6 months after femtolaser-assisted intrastromal implantation of MyoRing

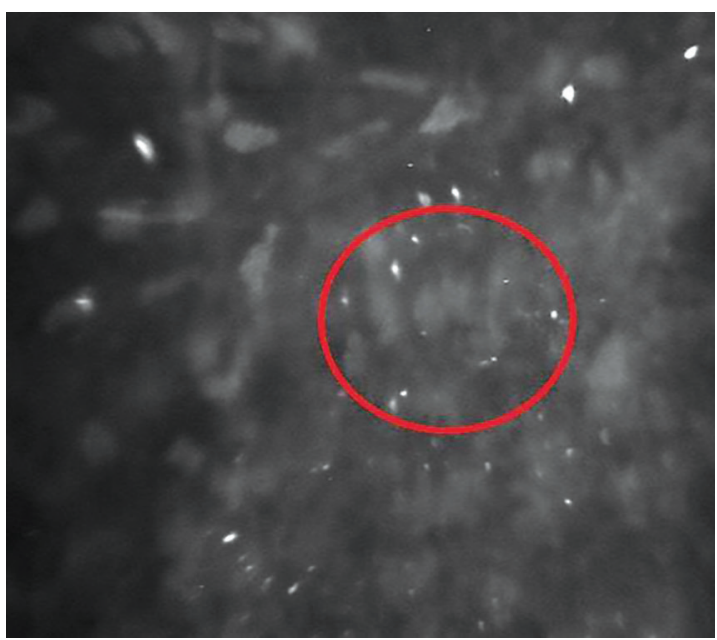

Fig. 11: Confocal microscopy solitary hyperreflective spots 12 months after femtolaser-assisted intrastromal implantation of MyoRing

\section{REFERENCES}

1. Daxer A. Adjustable intracorneal ring in a corneal pocket for keratoconus. J Refract Surg 2010 Mar;26(3):217-221.

2. Daxer A, Mahmoud H, Venkateswaran RS. Intracorneal continuous ring implantation for keratoconus: one year follow-up. J Cataract Refract Surg 2010 Aug;36(8): 1296-1302.

3. Daxer A. MyoRing for central and noncentral keratoconus. Int J Kerat Ect Cor Dis 2012 May-Aug;1(2):117-119.

4. Daxer A. Corneal thickness after MyoRing implantation for keratoconus. Int J Kerat Ect Cor Dis 2014 Jan-Apr;3(1):15-19.

5. Daxer B, Mahmood H, Daxer A. MyoRing treatment for keratoconus: DIOPTEX PocketMaker vs Ziemer LDV for corneal pocket creation. Int J Kerat Ect Cor Dis 2012 Sep-Dec;1(3): 151-152.

6. Janani L, Jadidi K,MosaviSA, NejatF, Naderi M,NourijelyaniK. MyoRing implantation in keratoconic patients: 3 years followup data. J Ophthalmic Vis Res 2016 Jan-Mar;11(1):26-31.

7. Sinitsyn MV, Pozdeyeva NA, Pashtayev NP. Comparative analysis of the intrastromal MyoRing implantation performed with the femtosecond laser. Int J Kerat Ect Cor Dis 2017 Jul-Dec;6(2):49-57. 